\title{
Correction to: Transcriptome-wide study of TNF-inhibitor therapy in rheumatoid arthritis reveals early signature of successful treatment
}

\author{
James Oliver ${ }^{1 \dagger}$, Nisha Nair ${ }^{1+}$, Gisela Orozco', Samantha Smith', Kimme L. Hyrich ${ }^{2,3}$, Ann Morgan ${ }^{4}$, John Isaacs5, \\ Anthony G. Wilson ${ }^{7}$, BRAGGSS, Anne Barton ${ }^{1,2+}$ and Darren Plant ${ }^{1,2^{*}}$
}

Correction to: Arthritis Res Ther 23, 80 (2021)

https://doi.org/10.1186/s13075-021-02451-9

Following publication of the original article [1], the authors reported an error in the spelling of the first author. The surname "Oliver" has been spelt with capital 'I' for India instead of an 'l' for Lima.

The original article has been corrected.

\section{Author details}

${ }^{1}$ Versus Arthritis Centre for Genetics and Genomics, Centre for Musculoskeletal Research, Manchester Academic Health Sciences Centre, The University of Manchester, Manchester, UK. ${ }^{2}$ NIHR Manchester BRC, Manchester University Foundation Trust, Manchester, UK. ${ }^{3}$ Versus Arthritis Centre for Epidemiology, Centre for Musculoskeletal Research, Manchester Academic Health Sciences Centre, The University of Manchester, Manchester, UK. ${ }^{4}$ Leeds Institute of Rheumatic and Musculoskeletal Medicine, University of Leeds and NIHR Leeds Musculoskeletal Biomedical Research Unit, Leeds Teaching Hospitals NHS Trust, Leeds, UK. Institute of Cellular Medicine, Newcastle University, Newcastle upon Tyne, UK. ${ }^{6}$ National Institute for Health Research Newcastle Biomedical Research Centre at Newcastle upon Tyne Hospitals NHS Foundation Trust and Newcastle University, Newcastle upon Tyne, UK. ${ }^{7}$ UCD School of Medicine and Medical Science, Conway Institute, University College Dublin, Dublin, Ireland.
Published online: 08 May 2021

\section{Reference}

1. Oliver J, Nair N, Orozco G, et al. Transcriptome-wide study of TNF-inhibitor therapy in rheumatoid arthritis reveals early signature of successful treatment. Arthritis Res Ther. 2021;23:80 https://doi.org/10.1186/s13075-02102451-9.

The original article can be found online at https://doi.org/10.1186/s13075021-02451-9.

* Correspondence: darren.plant@manchester.ac.uk

${ }^{+}$James Oliver and Nisha Nair are equal first authors.

Anne Barton and Darren Plant are equal last authors.

${ }^{1}$ Versus Arthritis Centre for Genetics and Genomics, Centre for

Musculoskeletal Research, Manchester Academic Health Sciences Centre, The University of Manchester, Manchester, UK

${ }^{2} \mathrm{NIHR}$ Manchester BRC, Manchester University Foundation Trust, Manchester, UK

Full list of author information is available at the end of the article

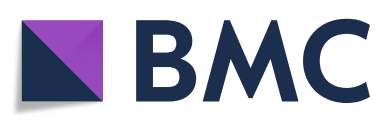

(0) The Author(s). 2021 Open Access This article is licensed under a Creative Commons Attribution 4.0 International License, which permits use, sharing, adaptation, distribution and reproduction in any medium or format, as long as you give appropriate credit to the original author(s) and the source, provide a link to the Creative Commons licence, and indicate if changes were made. The images or other third party material in this article are included in the article's Creative Commons licence, unless indicated otherwise in a credit line to the material. If material is not included in the article's Creative Commons licence and your intended use is not permitted by statutory regulation or exceeds the permitted use, you will need to obtain permission directly from the copyright holder. To view a copy of this licence, visit http://creativecommons.org/licenses/by/4.0/. The Creative Commons Public Domain Dedication waiver (http://creativecommons.org/publicdomain/zero/1.0/) applies to the data made available in this article, unless otherwise stated in a credit line to the data. 